\title{
¿Visión de los vencidos o falsificación? Datación y autoría de la tragedia de la muerte de Atahuallpa
}

Vision des vaincus ou falsification? Datation et paternité de la tragédie de la mort d'Atahuallpa

Vision of the vainquished or falsification? Dating and authorship of the tragedy of Atahuallpa's death

\section{César Itier}

\section{OpenEdition}

\section{Journals}

Edición electrónica

URL: http://journals.openedition.org/bifea/7367

DOI: $10.4000 /$ bifea. 7367

ISSN: 2076-5827

\section{Editor}

Institut Français d'Études Andines

\section{Edición impresa}

Fecha de publicación: 1 abril 2001

Paginación: 103-121

ISSN: 0303-7495

\section{Referencia electrónica}

César Itier, « ¿Visión de los vencidos o falsificación? Datación y autoría de la tragedia de la muerte de Atahuallpa », Bulletin de l'Institut français d'études andines [En línea], 30 (1) | 2001, Publicado el 08 abril 2001, consultado el 08 diciembre 2020. URL : http://journals.openedition.org/bifea/7367 ; DOI : https://doi.org/10.4000/bifea.7367

\section{(c) $(1) \odot$}

Les contenus du Bulletin de l'Institut français d'études andines sont mis à disposition selon les termes de la licence Creative Commons Attribution - Pas d'Utilisation Commerciale - Pas de Modification 4.0 International. 


\section{¿VISIÓN DE LOS VENCIDOS O FALSIFICACIÓN? DATACIÓN Y AUTORÍA DE LA TRAGEDIA DE LA MUERTE DE ATAHUALLPA}

César ITIER*

\section{Resumen}

Mediante un análisis filológico y textual, este artículo muestra que la Tragedia de la muerte de Atahuallpa, obra dramática quechua publicada por el escritor boliviano Jesús Lara en 1957, no fue compuesta por un indígena en el siglo XVI, como lo afirmó Lara y como lo han creído algunos autores después de él, sino que el mismo Lara la escribió enteramente con el fin de demostrar que los Incas habían poseído una gran literatura, cuya herencia subsistía todavía en Bolivia. Se identifican aquí las principales fuentes que utilizó el autor para forjar su falsa tragedia incaica.

Palabras claves: Teatro, quechua, Bolivia, inca, indigenismo, falsificación literaria.

\section{VISION DES VAINCUS OU FALSIFICATION?}

\section{DATATION ET PATERNITÉ DE LA TRAGÉDIE DE LA MORT D'ATAHUALLPA}

\section{Résumé}

À travers une analyse philologique et textuelle, cet article montre que la Tragédie de la mort d'Atahuallpa, oeuvre dramatique quechua publiée par l'écrivain bolivien Jesús Lara en 1957, n'a pas été composée par un indigène au XVI siècle, comme l'affirmait Lara et comme l'ont cru quelques auteurs après lui, mais qu'elle a été entièrement écrite par Lara lui-même qui voulait prouver que les Incas avaient développé une grande littérature, dont l'héritage subsistait en Bolivie. Sont identifiées ici les principales sources utilisées par l'auteur pour forger sa fausse tragédie incaïque.

Mots clés : Théâtre, quechua, Bolivie, inca, indigénisme, falsification littéraire.

\section{VISION OF THE VAINQUISHED OR FALSIFICATION?}

\section{DATING AND AUTHORSHIP OF THE TRAGEDY OF ATAHUALLPA'S DEATH}

This article is a philological and textual analysis of The Tragedy of Atahuallpa's Death, a drama published by the Bolivian novelist Jesus Lara in 1957. The author shows that this work was not composed by an Indian in the sixteenth century, as Lara claimed and as many other writers after him have believed, but was entirely written by Lara himself as he wished to prove that the

${ }^{*}$ Institut National des Langues et Civilisations Orientales (INALCO, París), 2 rue de Lille, 75343 Paris, cedex 07 y Centre d'Études sur les Langues Indigènes d'Amériques (CELIA-CNRS, París), 7 rue Guy Moquet, B.P. 8, 94801 Villejuif, cedex. E-mail: cesar.itier@wanadoo.fr 
Incas developed a great literature and that the heritage of this literature survived in Bolivia. The principal sources Lara used to establish his false Incaic tragedy are identified in this article.

Key words: Theater, quechua, Bolivia, inca, indigenism, literary falsification.

La obra dramática quechua anónima Atau Wallpaj p’uchukakuyninpa wankan o Tragedia de la muerte de Atahuallpa —en adelante "Tragedia"—, publicada por el escritor boliviano Jesús Lara en 1957 (1), es actualmente considerada como el único testimonio que haya llegado hasta nosotros de una tradición dramática precolombina. Según Lara, esta obra habría sido compuesta por un sabio inca sobreviviente a la conquista, de acuerdo a las pautas del teatro incaico. Se habría conservado con relativa fidelidad, a través de una serie de copias que desembocó en el manuscrito que Lara dice haber encontrado en 1955 y que está fechado en Chayanta en 1871. La popularidad del hallazgo de Lara le debe mucho al libro de Nathan Wachtel, La vision des vaincus (1971). En efecto, Wachtel hizo suyas estas conclusiones y basó en la Tragedia su interpretación de la percepción que los indígenas peruanos del siglo XVI tuvieron de la conquista española (2). En 1983, Teodoro Meneses ofreció su propia traducción del texto (1983) y en 2000 Ricardo Silva-Santisteban publicó nuevamente la traducción de Lara. Ni Meneses ni Silva-Santisteban procedieron a una reevaluación del texto y, basándose en la autoridad de Lara, presentaron la obra como incaica. Como se verá a continuación, un examen filológico de la Tragedia muestra que ésta es mucho más reciente y que es posible identificar a su autor.

\section{EL PROBLEMA DEL MANUSCRITO}

No se conoce manuscrito alguno de la Tragedia, ni siquiera bajo la forma de una transcripción paleográfica. En efecto, Jesús Lara relata, en la presentación de su edición del texto, que el manuscrito de la obra le fue ofrecido a la venta, en 1955, por un tal Santiago Estrada, comerciante de una lejana provincia del departamento de Potosí (Lara, 1989: 23). Lara afirma haber tratado de gestionar su compra por la universidad de Cochabamba para lo cual fotocopió las primera y última páginas del manuscrito, reproducidas en su edición de 1957. Pero en vano: el dueño pedía un precio superior a las posibilidades económicas de la universidad y ésta no llegó a adquirir el preciado documento. Finalmente, Lara obtuvo que el señor Estrada le permitiera copiar el manuscrito a mano, en un lapso de tres días, en el alojamiento del comerciante. Pero Lara no realizó una transcripción paleográfica del texto sino una transliteración según el

(1) La citaremos aquí a través de su reedición de1989.

(2) N. Wachtel no utilizó otro testimonio que la Tragedia. Sin embargo, en 1960, asistió, en Oruro, a la representación de una obra tradicional sobre la muerte del Inca pero, sin duda porque ignoraba el quechua, no recogió libreto alguno ni ofreció en su libro la más mínima información sobre la versión que vio escenificarse. 
sistema gráfico establecido por el Congreso Indigenista de La Paz en 1954. Luego, el señor Estrada desapareció con el manuscrito y nunca más volvió a saberse de él, cosa extraña si se toma en cuenta que el descubrimiento de Lara despertó un gran interés en Bolivia y en el ámbito académico internacional. Fuera de las dos páginas cuyas fotocopias están reproducidas en la edición de 1957, sobre las cuales volveremos, la edición transliterada de Lara no ofrece ninguna información sobre las grafías originales y los eventuales problemas de identificación que se le pudieran presentar al quechuista boliviano al transliterar el manuscrito. Su edición no contiene una sola nota ni un solo comentario de carácter filológico .

\section{LA TRAGEDIA Y LOS TEXTOS DRAMÁTICOS RELACIONADOS CON ELLA}

La Tragedia no constituye una manifestación literaria aislada y sabemos que, desde la época colonial, en varios pueblos de la sierra central del Perú y de la región de Oruro, Potosí y Cochabamba, en Bolivia, se venían representando obras sobre el tema de la muerte y la captura del último Inca. La primera noticia de las representaciones bolivianas que figura en la bibliografía es la que proporciona Mario Unzueta en su novela Valle (1945), donde ofrece una breve descripción y una traducción al castellano de algunos pasajes de una representación que presenció en Toco, en el valle de Cliza (dept. de Cochabamba) (Unzueta, 1945: 134-143). Lara afirma haber copiado, en 1952, el libreto de un drama sobre ese mismo tema procedente de San Pedro de Buena Vista (provincia de Charcas, dept de Potosí). En 1955, Clemente Balmori publicó el libreto de una obra titulada La conquista de los españoles, que se representaba anualmente en Oruro, en época de Carnaval, en honor a la Virgen del Socavón. Se trata de la primera publicación de un texto quechua asociado con esta tradición.

A principios de ese mismo año, el quechuista peruano César Guardia Mayorga consiguió un libreto sobre el tema de la muerte del Inca, en Santa Lucía (provincia de Cliza, dept de Cochabamba), y se lo prestó a Jesús Lara. En 1963, Guardia Mayorga publicó un texto, que presentó como su descubrimiento de Santa Lucía, en una revista mimeografiada de circulación confidencial. En 1983, Teodoro Meneses reeditó ese mismo texto, con su propia traducción, bajo el título de "Debate de Incas" (en adelante Debate). Curiosamente, el texto publicado por Meneses no corresponde en absoluto a la descripción que Lara hizo, en su libro de 1957, del texto descubierto en Santa Lucía por Guardia Mayorga. Debate corresponde más bien a la descripción que el escritor boliviano hizo del texto de San Pedro de Buena Vista copiado por él mismo. ¿Lara confundió e invirtió en su libro las indicaciones de procedencia de los dos manuscritos? (3). En tal caso, la versión que Lara describió como de San Pedro sería en realidad la de Santa Lucía y vice versa. Habría que admitir entonces que Lara aún no se había percatado de su error en 1961, cuando, en La literatura de los quechuas volvió a describir de la misma manera los dos textos. Sin embargo, esta hipótesis no explica un

(3) Es la conclusión a la que llega Jean-Philippe Husson (1997: 173-175). 
hecho esencial: si Guardia Mayorga y Meneses realmente publicaron el texto recogido por el primero, el de Santa Lucía, ¿por qué éste se encuentra transcrito según el sistema gráfico de Jesús Lara, que no coincidía de ninguna manera con el de Guardia Mayorga ni con el de Meneses? Es mucho más probable que el manuscrito publicado por Guardia Mayorga y Meneses no sea el que descubrió Guardia Mayorga sino el manuscrito de San Pedro descubierto por Lara. En efecto, éste señaló haber realizado una copia, transliterada según su propio sistema gráfico, del manuscrito de San Pedro que él mismo había encontrado. Por una razón que desconocemos, Lara le habría entregado al quechuista peruano una copia del manuscrito de San Pedro en lugar del manuscrito de Santa Lucía o de una copia del mismo (4).

Más recientemente, Margot Beyersdorff ha publicado una versión normalizada de otro libreto, procedente de Challacollo, fechado en 1952 (s.f.: 299-359). Por lo tanto, fuera de la Tragedia, se conocen actualmente tres textos dramáticos bolivianos sobre el tema de la muerte de Atahuallpa. Todos están vinculados con representaciones. En cambio, no existe indicio alguno de que el texto de la Tragedia haya sido alguna vez escenificado. Los tres libretos conocidos presentan muchos puntos en común y pueden considerarse como variantes de una misma tradición textual. Las variaciones que se observan entre ellos son lo suficientemente marcadas para que no puedan achacarse solamente a errores de copistas. Se explican por haber sido los textos objeto de las intervenciones voluntarias de copistas-directores de escena que buscaban "mejorarlos" desde un punto de vista lingüístico, literario, dramático, histórico o ideológico. En efecto, en los pueblos donde se escenifican, estos textos anónimos no se perciben como el legado intocable de un pasado sagrado o de un autor insuperable sino como una tradición actualizable. Lara mismo refiere que el poseedor del manuscrito de San Pedro, Gerardo Tapia, le pidió que introdujera en el texto las enmiendas y adiciones que le parecieran convenientes, a lo que Lara declara no haberse prestado (1989: 19) (5). El escritor boliviano consideraba la Tragedia como una versión mucho más cercana a lo que fuera el original del siglo XVI que Conquista y el manuscrito de San Pedro (= Debate). Si bien la Tragedia presenta muchos elementos textuales en común con los tres libretos que hemos mencionado - lo que muestra que su génesis no fue independiente de ellos-, es mucho más distinta de cualquiera de ellos de lo que son los tres libretos entre sí.

Una de las singularidades de la Tragedia es que está íntegramente en quechua. En cambio, casi el 50\% del texto de las otras tres versiones está en español. Los libretos tradicionales son bilingues y en ellos los españoles hablan en castellano y los indígenas en quechua. En la Tragedia, hablan solamente los indígenas mientras que los españoles se limitan a mover los labios, a excepción de la escena final en que Pizarro y el Rey de España dialogan en quechua, hecho inaudito en las demás versiones para personajes españoles. Las acotaciones, el título y todo el aparato paratextual de la Tragedia son en quechua. Lo que a primera vista podría parecer normal para una obra en ese idioma constituye en realidad un hecho sorprendente y único entre todas las obras dramáticas

(4) Margot Beyersdorff, quien parece haber tenido acceso al manuscrito de San Pedro, llega a la misma conclusión en su libro (s.f.: 193).

(5) Beyersdoff refiere prácticas semejantes (s.f.: 229). 
quechuas de cualquier época. En efecto, quienes eran capaces de leer un texto quechua forzosamente también sabían castellano — si no, ¿cómo hubieran aprendido a leer y escribir?-. El paratexto, que no tenía presencia en la representación, no tenía necesidad de venir en la lengua indígena. Más bien, al no existir una tradición de leer y escribir acotaciones en quechua, éstas hubieran constituido una dificultad gratuita tanto para el autor como para los actores. Estos hechos sugieren una intervención erudita y purista en la elaboración de la Tragedia acompañada, tal vez, de una voluntad de mistificación no muy bien pensada.

Por añadidura, como se puede ver en la fotocopia de la primera página del manuscrito, los nombres propios españoles están quechuizados en un grado extremo, desconociendo la representación de las vocales abiertas e y o: Pisarru, Yspaña, Almagru, padre Ualbirde, Filipillu, Jisu Cristu, Uarsiluna. Éstas son formas sumamente abstractas e ideales, que no corresponden a lo que realmente pronuncian los quechuahablantes monolingües cuando reproducen un término castellano. Recuerdan más bien la manera cómo los quechuistas modernos imaginan que deberían pronunciarse los términos procedentes del castellano si se los adaptara totalmente al sistema fonológico quechua. Estas formas suponen un copista o un autor altamente consciente del valor fonético de los signos vocálicos del castellano y del sistema fonológico del quechua.

\section{LALENGUA DELA TRAGEDIA:ELQUECHUABOLIVIANOMODERNO}

La Tragedia no presenta ninguna huella de consonantes etimológicas en posición final de sílaba. En este aspecto, no conserva indicio alguno de un estado de lengua anterior al fenómeno de erosión de esas consonantes, que se consumió en el siglo XVIII. Desde un punto de vista morfosintáctico, la lengua de la Tragedia corresponde totalmente al quechua boliviano moderno, con formas y combinaciones ajenas a la lengua del siglo XVI tal como la atestiguan los documentos conocidos. Un repaso exaustivo de las características que le dan su perfil moderno sería demasiado extenso. Me limitaré a señalar los elementos que la tipifican de manera más resaltante como quechua específicamente boliviano.

El paradigma de personas verbales corresponde totalmente a esta variedad: la marca de $1^{\text {a }}$ persona exclusiva en futuro es -sqayku (en vez de -saq-ku en la lengua general y en las hablas modernas del sur del Perú); la $3^{\text {a }}$ persona plural en futuro es -nqa-nku (en vez de -nqa-ku); la marca de $3^{\mathrm{a}}$ persona sujeto con $1^{\mathrm{a}}$ persona del plural exclusivo objeto es -wayku (en lugar de -wa-n-ku). El genitivo después de consonante presenta la triple forma - pa, paq y -pata (en vez de - pa o -paq). La Tragedia hace un uso restringido de los sufijos modales, en particular del asertivo V- $n$ / C - $m i$, como en el quechua puneño y boliviano actual. En cambio la antigua lengua general, como todavía las variedades de Cuzco y Ayacucho, delimita y estructura la mayoría de enunciados con el asertivo, el citativo V-s / C-si o el conjetural V-ch / C-cha. Cuando aparece en la Tragedia, el asertivo tiene muchas veces la forma redundante - $m i-n$ después de consonante, característica del quechua boliviano moderno. Como en el quechua cochabambino moderno, encontramos en la Tragedia cierta flexibilidad en el orden 
respectivo de las marcas de posesivo y de plural. Por una parte, se da el orden general del quechua: churi-yki-kuna "tus hijos" (6) (p. 54). Pero más a menudo aparece el orden inverso, no atestiguado en las fuentes antiguas ni en los dialectos peruanos: wak'a-kunanchij "nuestros dioses" (p. 58), runa-kúna-y "mis vasallos" (p. 56). Ciertas marcas de personas sujeto-objeto se encuentran absolutamente unidas y postpuestas a las marcas de tiempo y a ciertos nominalizadores: (kamachiy) willa-na-wanchij-ta "(ordena) que nos revele" (7) (p. 84, en vez de willa-wa-na-nchik-ta en la lengua general y los modernos dialectos surperuanos), rupha-rqa-sunki "te abrasó" (p. 104) en vez de ruphasu-rqa-nki en la lengua general). Probablemente ello se deba a una influencia del aymara cuyas marcas verbales de personas sujeto-objeto suelen ser más sintéticas que las del quechua. Dentro del quechua sureño, la emergencia de -su-como marca de $2^{\mathrm{a}}$ persona objeto es un fenómeno propio del quechua boliviano y argentino. Esta marca está sistemáticamente empleada en la Tragedia: sayarisunqa 'te asistirá" (p. 116), (kausayniykita) qhechúsuj "quien te quitase (la existencia)" (p. 124), amaraq [...] mikhu-yka-ka-pu-sqa-su-jti-n-ku "antes de que vaya a devorarte" (p. 98), amaraq [...] chinka-chi-su-sqá-jti-y "antes de que [...] vaya a terminar contigo" (p. 104).

Como se observa en estos últimos dos ejemplos, la forma del progresivo es -sqaen todo el texto y en el mismo manuscrito donde aparece representado como <-sca-> Se trata de una forma propia del moderno quechua de Cochabamba (Lastra, 1968: 32, 34) (8) que constituye una evolución algo anómala, desde un punto de vista fonológico, de -chka-, progresivo común de los dialectos quechua II meridionales. Ya en La poesía quechua de 1947, el propio Jesús Lara creía que tal forma era antigua e incaica, interpretando equivocadamente la grafía <-sca-> de muchos documentos, que representa en realidad -ska- <-chka-. Así, la totalidad de los progresivos que aparecen en La poesía quechua y en La literatura de los Quechuas presenta esa forma radicalmente extraña a la lengua atestiguada por los textos antiguos.

La sintaxis manifiesta las mismas características bolivianas modernas, como el empleo de pronombres relativos mediante el sufijo interro-dubitativo -chus, probablemente creados a partir del modelo castellano. En los tres ejemplos que siguen se observa respectivamente los pronombres interrogativos imachus "qué", imatachus "qué (acusativo)" y imapajchus "para qué":

icha chaypi sut'ichaway,

imachus jamuwasun chayta. (p. 90)

imatachus kaypi munanku

chayta tapurimuchun (p. 94)

thuilla thuilla willaykuway

imapajchus ñiwan chayta. (p. 96) quizá entonces aclarar lograras

lo que ha de acontecer.

y les pregunte

qué es lo que en nuestra tierra quieren.

te pido que me digas sin tardanza

el motivo de su llamada.

(6) Citamos sistemáticamente en este artículo las traducciones del propio Lara.

(7) El empleo del acusativo en el complemento del verbo kamachi- "ordenar" constituye además un calco del castellano. En quechua, este verbo requiere un complemento marcado por el benefactivo -paq. Una frase correcta hubiera sido kamachiy willanawanchikpaq.

(8) Lo atestigua también Ruth Flores Pinaya (1991: 11). 
El léxico registra asimismo cantidad de formas exclusivamente bolivianas como imajtin "por qué", siminaku- "disputar entre dos personas", el empleo de tiya- para la expresión de la obligación: apánay tiyan "tengo que conducir" (p. 106). Fuera de algunos términos que no he podido identificar, existen unos pocos lexemas que no pertenecen al quechua boliviano: unu "agua", término propio del quechua puneño y cuzqueño, en vez de yaku en todas las demás variedades. Dada la pretensión purista del texto, la presencia de ипи y la ausencia de yaku se pueden explicar fácilmente por una voluntad de imitar el quechua cuzqueño. En efecto, el término unu es probablemente el rasgo distintivo del quechua cuzqueño más universalmente conocido por los hablantes de otros dialectos. Con algunos otros acomodamientos, que examinaremos a continuación, el quechua de la Tragedia corresponde enteramente al quechua boliviano moderno. Ahora bien, si el texto fuera el fruto de una tradición manuscrita que se remontara al siglo XVI, conservaría, pese a las intervenciones actualizadoras de los sucesivos copistas, algunas huellas de estados de lengua anteriores al boliviano moderno.

\section{UN QUECHUA PURISTA}

Otra diferencia lingüística entre las versiones tradicionales y la Tragedia es la cuasi ausencia de préstamos léxicos y morfológicos del castellano en ésta última mientras los libretos de representaciones presentan un gran número de préstamos, que corresponde al acervo lexical real del quechua boliviano moderno. Así, en la Tragedia, no aparece el plural $-s$, de origen español, totalmente asimilado por esta variedad. Sin embargo, ello no atestigua un estado de lengua anterior al de la asimilación de $-s$ por el quechua boliviano ya que, como lo veremos más adelante, el empleo del plural -kuna, en la Tragedia, corresponde al de $-s$ en quechua boliviano y no al que tiene en los dialectos que han conservado -kuna. La presencia y el empleo de -kuna en la Tragedia demuestra más bien una intervención purista y erudita en la elaboración del texto.

La Tragedia contiene asimismo una serie de términos obsoletos o que no se emplean en el quechua boliviano moderno con el sentido en que aparecen en este texto. A primera vista ello dejaría pensar en una mayor antigüedad de la Tragedia con respecto a las demás versiones. Sin embargo, los conceptos expresados por esos términos son en realidad conceptos del castellano, ajenos a lo que se conoce del quechua del siglo XVI. Algunos son adaptaciones o creaciones de los quechuistas de la colonia, siempre utilizadas por sus herederos de la república: pampachay "perdón" (9), janajpacha "cielo" (10), iñiy "creencia" (11), sami "ventura, dicha" (12). Otras son más modernas o son creaciones del autor de la Tragedia: pacha "tiempo" (13), taripakuy "justicia",

(9) p’uchukay panpachayllatapas/ patanman sullaykápuj ari "rocía, pues, sobre su cuerpo/ siquiera la postrera absolución" (p. 132).

(10) Sobre la adaptación, por los religiosos, de este término al sentido de "cielo", véase Estenssoro (1997: 66-69).

(11) Manañachu chaypachaqa/ kasqa iñiypas, taripakuypas,/ qasi qhespilla kaypas? “¿No había habido entonces ya/ ni creencia ni justicia,/ ni bienaventuranza?" (p. 144).

(12) samínchaj tukukapuñ̃a “tocó a su fin nuestra ventura" (p. 112); sami chaupipi "en medio de la dicha" (p. 144).

(13) pachawan atichikuylla "es simplemente perder tiempo" (p.130). 
Wiraqucha “Dios" (14), llimp'i- "pintar" (pp. 82, 86), aywariku- “despedirse” (p. 114), qhispiy simi "Biblia" (lit. "palabra de salvación", p. 90). Algunos términos existentes en el quechua boliviano moderno son empleados en contextos en los cuales se suele usar un préstamo en esa variedad, como rima- "hablar", en vez de parla- < esp. "parlar", que tiene el mismo sentido y es más usual, muchuchi- "hacer padecer" en vez de castiga-. Así, la expresión kunanqa muchuchisqan kanki "Ahora serás ajusticiado" (p.142) aparece como un sustituto de kunanqa castigasqan kanki que corresponde a lo que efectivamente se diría en el quechua boliviano actual. Ahora bien, la forma muchuchisqan kanki constituye un calco del castellano. La combinación del factitivo -chi- y del perfectivo -sqa dentro de una frase en futuro constituye un fenómeno inusual en quechua, del cual resulta una frase bastante oscura.

Curiosamente para un texto supuestamente antiguo, en el que los términos de origen castellano son casi ausentes, los verdaderos arcaismos lexicales, es decir los que no fueron forjados por eruditos, escasean en la Tragedia: mit'aysana "descendencia" (p. 146), thuilla "sin tardanza, al instante; instante" (pp. 86, 96, 102, 104, 108) (15), añayñi- "loar" (16), kiti “patria" (p. 102), pullkanka "rodela" (p. 120), y waminqa (17). Veremos más adelante cuál fue el origen de su presencia en la Tragedia.

Por lo tanto, la pureza aparente de la lengua de la Tragedia no es la de un texto anterior a la influencia del castellano en el quechua sino que se debe a una intervención erudita atenta sólo a los aspectos más superficiales de la lengua. En realidad, aparte de los nombres propios, el único préstamo que aparece en la Tragedia es tayta "padre”. Es de advertir que es también uno de los pocos que encontramos en el teatro quechua cuzqueño moderno: su origen castellano solía pasar inadvertido hasta para los autores más eruditos. Sin duda por la misma razón escapó del afán purista del quechuista que intervino en la elaboración de la Tragedia.

\section{INTERFERENCIAS CON EL CASTELLANO}

La huella subterránea del castellano es omnipresente en la Tragedia y supera ampliamente la que caracteriza la variedad actualmente hablada por los bilingües en las ciudades de Bolivia. Así, si bien algunos calcos del castellano forman ya parte del acerbo común de la variedad boliviana moderna, como en wañusqamanña rijch'awan "Paréceme que está ya muerto" (p. 144), otros constituyen fenómenos más individuales, como en el caso del empleo del plural verbal $-k u$. En efecto, en el quechua cuzqueño-boliviano, la concordancia de número en la relación sujeto-verbo es enteramente opcional para la tercera persona y, en la mayoría de los casos, no se realiza. En cambio, en la Tragedia es absolutamente sistemática, siguiendo en eso la pauta del castellano, como en el

(14) Mana. Nuqaykuqa jamuyku/sullullkaj Wiraquchata/ qankunawan rijsichinaykupaj "No. Nosotros venimos/ a hacer que conozcais/ al verdadero Dios" (p. 74).

(15) Aún así, en la p. 104, este término es usado en un contexto que no corresponde a su empleo en los textos coloniales sino al del préstamo ratu (< esp. "rato") en las variedades modernas: $u j$ thuillatan saqiriyki "te concedo un instante" para sustituir uj ratullatan saqiriyki.

(16) añayñisqa kamajniykitachu "tu loada voluntad" (p. 140).

(17) Jesús Lara se equivocó en la interpretación de las grafías originales. Los tres últimos términos deben interpretarse respectivamente como k'iti, pullqanqa y wamink'a. 
ejemplo siguiente: auqa q'illay runakuna/ch'ichimunku "hombres cubiertos de irritante hierro/ [...] han brotado" (pp. 58-59). Otro calco, al parecer inexistente en el quechua boliviano moderno, es la expresión ama chay uyata churaychu lit. "no pongas esa cara", traducida por Lara como "no muestres ese continente" (p. 108).

Un número importante de los calcos que encontramos en el texto afecta un nivel más profundo de la lengua e infringe aspectos fundamentales de su sistema. Sólo se explica por las condiciones específicas de una elaboración escrita del texto, en la cual un autor redacta en quechua pero piensa en castellano. Estos calcos se manifiestan en particular en el orden de las palabras, como se puede observar en el enunciado siguiente, acompañado de la traducción de Lara:

pay watuchun

kay chhallachata, auqasunk'aj

apachimusqanta apunchijman. (p. 84)
Que él descifre esta chala que el barbudo enemigo

le remitió a su señor.

Aquí, el modificador apunchijman "a nuestro señor" se halla postpuesto al grupo nominal auqasunk'aj apachimusqanta "lo que le remitió el barbudo enemigo", siguiendo el orden de la frase castellana que figura en la traducción. Ahora bien, en quechua, el orden de los constituyentes del sintagma nominal es muy rígido y el modificador (aquí apunchijman) de ninguna manera puede postponerse al núcleo del sintagma (aquí el grupo nominalizado auqasunk'aj apachimusqan) y menos aún al límite externo del sintagma (en este caso, el acusativo - ta) como sí lo hace aquí. Hubiéramos esperado la frase siguiente: pay watuchun kay chhallachata, auqasunk'aj apunchijman apachimusqanta.

Observamos exactamente el mismo fenómeno en esta frase:

purirísaj

mana samaspa tinkúnay kama

chay auqasunk'akunawan (p. 98)
Partiré, sin descanso

andaré hasta encontrarme

con los enemigos de barba...

Los constituyentes de este enunciado siguen un orden calcado sobre el de la frase castellana que Lara presenta como su traducción, pero que en realidad debemos considerar prácticamente como el original. Sin embargo, desde el punto de vista de la sintaxis del quechua, sólo cabe la posibilidad de ordenarlos de la manera siguiente: purirísaj mana samaspa chay auqasunk'akunawan tinkunaykama. En efecto, chay auqasunk'akunawan "con los enemigos de barba" forma parte de un sintagma nominal complejo y actúa como modificador del núcleo tinkunaykama "hasta encontrarme".

El siguiente fragmento muestra otra incoherencia sintáctica:

pacha k’anchaj Inti, máillij

Taytanchij, waqaychasunki

Sayri Túpaj

Qanmanpas jinallataj. (p. 80) el Sol que purifica y luz da al mundo, nuestro Padre, te guarde.

\section{Sayri Túpaj}

A ti lo mismo,...

Aquí, el adlativo -man es la traducción, morfema por morfema, de la preposición castellana "a" en "a ti lo mismo". Sin embargo, el verbo waqaychasunki "te guarde" 
induce normalmente un complemento en acusativo de forma que Sayri hubiera debido responder: Qantapas jinallataj. La misma incoherencia se repite en las pp. 82, 84, 120 y 122.

Estos ejemplos podrían multiplicarse y caracterizan a la obra en su integralidad (18). La Tragedia está compuesta en un quechua totalmente interferido por las estructuras del castellano, lo que muestra que no estamos ante una obra tradicional, indígena y antigua puntualmente requechuizada por un erudito. La Tragedia no pudo ser compuesta por un inca sobreviviente a la conquista. Es enteramente obra de un letrado bilingüe, cuya actividad intelectual se desempeñaba mayormente en castellano. El tipo de interferencias que hemos mencionado difícilmente se encuentra en textos de la época colonial, aun en los que escribieron los religiosos. Esos calcos semánticos y sintácticos, que derivan no pocas veces en enunciados incoherentes y oscuros, caracterizan más bien los textos elaborados por los quechuistas a partir de fines del siglo XIX. En su relación al castellano, la lengua de la Tragedia presenta las mismas características que la de algunos dramas quechuas cuzqueños de inicios del siglo XX: es purista a nivel de los significantes pero profundamente influenciada por el castellano en los niveles semántico y sintáctico, hasta el punto de infringir el sistema de la lengua (19).

En realidad, para quien tenga cierta familiarización con los textos coloniales, el carácter reciente de la Tragedia y su pertenencia a la tradición erudita moderna saltan a la vista. Margot Beyersdorff fue la primera en advertirlo y sugirió que su autor pudo ser el famoso quechuista boliviano del siglo XIX Carlos Felipe Beltrán, quien hubiera tomado como base algún "cartapacio" descubierto en una parroquia (Beyersdorff, s.f.: 190-192). Advierte que Beltrán declaró ser autor de una obra en quechua titulada "La muerte de Atahuallpa”. Sin embargo, M. Beyersdorff no presenta ningún otro argumento a favor de la tesis de la autoría de Beltrán. Un cotejo rápido de la lengua y del estilo de la Tragedia con la de las obras del gran quechuista boliviano - infinitamente mejor escritas que la obra publicada por Lara- muestra que Beltrán no fue el autor de la Tragedia (20).

\section{LA POESÍA QUECHUA DE LARA (1979[1947]), FUENTE DE LA TRAGEDIA}

La Tragedia contiene dos elementos léxicos dialectalmente ajenos al quechua boliviano moderno y aun al cuzqueño y puneño: wamra "muchacho, muchacha" y willka "nieto" (p. 90). Los encontramos, en cambio, en variedades más septentrionales

(18) Husson sólo detectó algunas interferencias y concluye: "l’erreur serait de généraliser un résultat partiel en le présentant comme caractéristique de l'oeuvre dans son intégralité” (1997: 91).

(19) Sobre este fenómeno, véase Itier, 2000.

(20)Por añadidura, Beltrán escribe: "Para ensayar mejor las fuerzas del quichua, para manifestarla como lengua cultivable, he escrito un drama 'El triunfo de la inocencia' y la tragedia 'La muerte de Atahuallpa' en que los diálogos entre indios o con indios son en quichua” (Beltrán, 1891: 2). Esta frase sugiere que la obra sólo es parcialmente en quechua y que los diálogos entre conquistadores son en castellano, lo que no corresponde a la Tragedia. 
como el actual quechua ayacuchano (21). ¿Cómo explicar su presencia en un texto por lo demás tan característicamente boliviano? La Tragedia contiene otras dos formas no atestiguadas en las descripciones del quechua boliviano ni en las de ninguna otra variedad quechua moderna: la interjección ayauya "ay", muchas veces repetida en la obra, y el morfema -jsa- de dudosa interpretación (22). La única fuente que atestigua la existencia de estos dos elementos es un texto quechua varias veces presentado, con algunas variantes, por Felipe Huaman Poma en su Nueva Coronica. El morfema que Lara transcribe como -jsa- aparece en ésta como <-csa-> (23) dentro de una estructura idéntica a la de los enunciados en los cuales aparece en la Tragedia (24). Los textos de Huaman Poma que contienen estos elementos están reproducidos en la antología que acompaña La poesía quechua de Jesús Lara (25). ¿Conocía el autor de la Tragedia la Nueva Coronica o el libro de Lara? Al parecer sí ya que el término wamra se encuentra también en el mismo texto que -ayauya y -jsa-, y que willka "nieto" se encuentra en una de las oraciones de Pachacuti también reproducida por Lara. No debe ser casualidad que el término que precede inmediatamente willka, en el mismo texto de Pachacuti, es mit'aysanay "hijos, descendencia", uno de los arcaismos que hemos detectado anteriormente en la Tragedia. Ahora bien, Huaman Poma y Pachacuti son los únicos autores indígenas cuyos textos reproduce Lara. Por lo tanto, su autoridad en materia incaica debió parecerle al autor de la Tragedia mayor que la de cualquier otro texto contenido en La poesía quechua. Es bastante obvio que el autor de la Tragedia buscó en ellos algunos elementos que le dieran a la obra dramática un toque incaico.

Existe otro indicio que consolida la hipótesis de que el autor de la Tragedia utilizó La poesía quechua de 1947. En la Tragedia se usa reiteradamente el verbo kama-, obsoleto en el quechua boliviano actual fuera de su uso cristiano de "crear". Tiene ahí el sentido de "mandar" que no corresponde en absoluto al sentido histórico de ese verbo:

Inkallay, qhápaj atiyniyki

jinantinta kámaj karqa (p. 138)

Imarayku kamanayman

jallp'ayman rikurimunku? (p. 60)
Inca mío, tu poder ínclito

mando ejercía en todo el mundo

¿Por qué vienen a hollar mi tierra

mis dominios aquellos hombres?

(21) Sobre esta observación, Husson desarrolla la tesis de un origen "chinchaysuyano" de la Tragedia (1997).

(22) kallpajsaykita quway "dame valor" (p. 132).

(23) <unocsayquita yacucsayquita cachallamouay> fol. 191. En los folios 285 y 1161, Huaman Poma reproduce variantes del mismo texto en la que figuran respectivamente <yacullayquita cacharimouay> y <unolaykita cacharimouay>, es decir el morfema restrictivo -lla- en lugar de $<-c s a->$ en la primera variante. Es muy probable que la forma <-csa-> corresponda al actual diminutivo - cha de los dialectos del sur del Perú. Esa forma tal vez manifieste un esfuerzo, de parte de Huaman Poma, por transcribir la africada retrofleja de una variedad quechua local en proceso de absorbción por la lengua general.

(24) unujsaykita, yakujsaykita kachallamúway "manda, pues, el prodigio de tus aguas,/ Manda, pues, la merced de tus lluvias" (reproducimos aquí la transliteración y la traducción de Lara en La poesía quechua, (1979[1947]): 159).

(25) (1979[1947]): 62, 70, 100, 158 para ayauya y 159 para -jsa-. 
Manachu qanqa yachanki

Intitapas, Killatapas

payllan kamaj kasqantaqa (p. 72)

Ispáñaj kamájnin (p. 100)
¿Acaso tú no sabes

que él es el único que incluso puede

con el Sol y la Luna?

rey de España

Ahora bien, en La poesía quechua, ése es exactamente el sentido que Lara le da, equivocadamente, al verbo kama- cada vez que no le parece adecuada la glosa "crear", en particular en su traducción de los textos de Pachacuti: Pachakámaj "gobierno del mundo" (p. 157), Wiraqocha kámaj "Dios que gobierna" (p. 158), Pachakamajta "al regidor del mundo" (p. 159). Las cuatro frases de la Tragedia que hemos citado anteriormente no dejan lugar a otras interpretaciones para el verbo kama-y muestran que el texto de la obra dramática fue escrito con la idea de que kama- significaba "ordenar". El verbo añayñi- que encontramos en la Tragedia (p. 120) con el sentido de "loar" también figura en la antología de La poesía quechua, p. 160: añayñispanñan (26)/ wiraqochata "Está rindiendo su alabanza/ A Wiraqocha", añaynisunki "te rinde su alabanza". Estas coincidencias confirman que el autor de la Tragedia debía conocer $L a$ poesía quechua de 1947.

\section{OLLANTAY, FUENTE DE LA TRAGEDIA}

Los arcaismos que no proceden de los textos publicados por Lara en La poesía quechua proceden de Ollantay, del cual Lara ofreció una edición en 1971 (Anónimo, 1971): pullkanka "escudo" (1971: 76), waminqa "capitán" (1971: 48, 70, 96, 102, 104, 132, 138, 140, 178, 180, 182) y k'iti "país, región, contorno" (1971: 84, 134) (27). En Ollantay se encuentra también el modelo métrico de los cantos de las ñustas en Tragedia (1989: 64, 66, 108, 134, 136) que constituyen los únicos fragmentos que presentan un elemento de versificación en esta obra y cuya estructura no tiene equivalente en los libretos tradicionales (28). Compárese este fragmento del primer harawi de Ollantay, según la edición de Lara, con la de dos cantos de ñustas en la Tragedia:
Ollantay
Tragedia
Tragedia

Ama p'isqo, mikhuychu, tuyallay, tuyallay,

ñust'allaypa chajranta, tuyallay, tuyallay.

Manan jina tukuychu
Auqakuna chayamusqanku, Inkallay, mamaqhucha patallanta. Inkallay, Imaraykun aquyraki ima aquyrakin chijchimun,

Inkallay, sapan apullay.

Jatun sach'a siriykapun,

Inkallay, sapan apullay.

Llantuykipin káusaj kayku,

(26) Corregido en La literatura de los quechuas como añayñisqanñan (p. 192).

(27) A excepción de thuylla thuylla "rápidamente" que procede de Debate: 28, 33.

(28) Como lo resaltó el mismo Lara: "El recurso lírico del estribillo que aparece en el primer arawi del Ollántay se nos ofrece reiteradamente en el wanka.” (1989: 43). 
tuyallay, tuyallay, Inkallay, Inkallay, sapan apullay, jillurina saranta, p’unchaunínchijta úshpaj jamun, qan p'unchauniyku karqanki, tuyallay, tuyallay, Inkallay, Inkallay, sapan apullay.

(1971: 58-60)

No comas, no, pajarillo, Habían llegado adversarios, tuyita mía, tuyita mía, en el predio de mi infanta,

tuyita mía, tuyita mía.

No vayas a consumir, tuyita mía, tuyita mía, el apetecible maiz, nuestro día,
Inca mío,

por encima del mar,

Inca mío,

Por qué la desventura,

Inca mío.

a agrisar viene nuestros días, tuyita mía,tuyita mía. qué infortunio graniza, Inca mío, mi solo señor.

Se ha reclinado el árbol

grande,

Inca mío, mi solo señor.

Era a tu sombra que vivíamos,

Inca mío, mi solo señor, Inca mío, fuiste tú

Inca mío, mi solo señor.

\section{VALLE DE MARIO UNZUETA (1945), FUENTE DE LA TRAGEDIA}

La novela Valle contiene la traducción al castellano de algunos fragmentos del texto dramático que se representaba anualmente en el pueblo de Toco (provincia de Cliza, dept. de Cochabamba). El texto castellano proporcionado por Unzueta encuentra paralelos muy estrechos en el texto quechua de la Tragedia:

\section{Valle Tragedia Tragedia traducida por Lara}

Soñé que hombres de hierro, Yananchasqa muspayniypi saliendo de la tierra,

robaron nuestros templos. El cielo y los cerros eran rojos como el pecho del nina-pilco.

han arrasado nuestras casas, y han saqueado codiciosos templos de oro

\section{auqa q'illay runakuna} destruyeron nuestras casas y

ch'ichimunku míllay míllay kikin jallp'a uramanta,

llapata waykapayanku, janajpachari, urqukunari pukalla pukalla rauranku
Durante los dos sueños hombres cubiertos de irritante hierro innumerables han brotado como de las entrañas de la tierra, wasinchijta wankurqayanku, llapa wak'akunanchijpa quri wasinkunatari $1 \quad \mathrm{o} \quad \mathrm{s}$ de todos nuestros dioses, y el cielo y las montañas han ardido con llamas rojas, 
kikin pillkuj qhasqun jina. (p. 58)

Veamos otro caso:

Valle

Tragedia

rojas comoelpechodel pillku.

- Huaylla Huisa, mi hermano,

Waylla Wisa, puñuj apu inka, Waylla Wisa, Inca que

tú que has vivido por mucho

tiempo solo en nuestras

sispa wawqichay,

durmiendo agora,

montañas para estar más cerca

de nuestro Padre el Sol; tú que

sabes lo que hablan esas

qan sayarqanki sapallayki

mi primo hermano,

wayma pachata urqullapi

tú resisdiste solitario

antaño en las montañas

asllatawan sispanaykipaj

para hallarte más cerca

montañas; tú que has oído, de

máyllij Inti Taytanchijman.

las bocas secas de las

del Sol, nuestro Padre que

lava.

chullpas, cosas que ningún

Qan yachanki imatachus

hombre escuchara, acércate.

chay urqukuna rimanku.

Qan uyarinki chullpakunaj

ch'arkiyasqa siminmanta

manan pij uyarisqanta.

Kunan qayllámuy, uyaríway. Acércate ahora, y óyeme.

(p. 58)

Tú sabes lo que hablan

esas montañas.

Tú escuchas de la boca

áspera de las chullpas

lo que nadie ha escuchado.

En este ejemplo, se muestra que el texto quechua de la Tragedia no es sino la traducción del texto español de Valle y no al revés. En efecto, el texto quechua sigue tan literalmente el texto castellano que llega a quebrantar la sintaxis de la lengua. Así, el modificador mayllij Inti Taytanchijman "del Sol, nuestro Padre que lava" debería preceder asllatawan sispanaykipaj "para hallarte más cerca", por los motivos ya expuestos más arriba.

Lo mismo se advierte en esta réplica de los españoles en Valle que, en Tragedia, se encuentra en boca del intérprete Felipillo:

Valle

- Hemos venido mandados

por el Rey más poderoso de la

tierra, al que deben obedecer

todos los hombres.

(p. 139)
Tragedia

Aswan tijsi muyumanta

atipaj apu kachamuwayku.

Llapa llapa runakuna

payllatamin uyarinanku.

(p. 72)
Tragedia traducida por Lara

Por el señor más poderoso

delmundovenimosenviados.

Todos los hombres a él le

deben

ciega obediencia. 
En quechua, esta frase es oscura: el orden de los constituyentes del sintagma nominal (Aswan tijsi muyumanta atípaj apu "el señor más poderoso de la tierra") no se atiene al sistema de la lengua y el empleo del ablativo -manta en tijsi muyu "mundo" no es sino un calco de la expresión española "del mundo". En realidad, el adverbio aswan "más" debería preceder inmediatamente al adjetivo atípaj “poderoso", al cual determina, у tijsi тиуи requeriría el locativo -pi. La frase correcta sería: tijsi muyupi aswan atípaj apu kachamuwayku. Los defectos y los calcos que se advierten en el texto quechua indican que el parentesco estrecho que existe entre los textos de Valle y la Tragedia no se debe a que Unzueta haya tenido acceso a una versión cercana a la de Tragedia sino a que muchos fragmentos de Tragedia son una (mala) traducción al quechua de los de Valle. De hecho, la versión proporcionada en castellano por Unzueta es más cercana a la Tragedia que Conquista y Debate. Más aún, casi todo el texto de Valle se encuentra traducido al quechua en la Tragedia.

\section{EL AUTOR DE LA TRAGEDIA}

¿Quién fue el autor de la Tragedia? Hemos mostrado que éste debía conocer a la vez Ollantay, Valle y La poesía de los quechuas. Existen también evidencias de que conocía Conquista y Debate. En la Bolivia de la década de 1950 parece no haber habido otro quechuista más que Lara que pudiera tener acceso a todas estas fuentes y ser capaz de elaborar un texto que tuviera esa envergadura. En realidad, ya desde su libro de 1947, el propio Lara dejó ver que se habían borrado para él las fronteras entre deseo y realidad. En efecto, cuando publicó La poesía quechua, aún no había "descubierto" la Tragedia y no conocía de esa tradición dramática más que la descripción y traducción al castellano de algunos fragmentos que publicara Mario Unzueta en su novela Valle. Sin embargo, dejó escapar algunas afirmaciones que muestran que el texto quechua ya existía para él: "el poema se halla compuesto en un quechua de asombrosa pureza" (Lara, 1979 [1947]: 67), "Este poema se presenta, pues, como el testimonio que hacía falta, por su carácter de inobjetable, para probar en última instancia la existencia de una gran cultura poética entre los quechuas precolombinos." (Lara, 1979[1947]: 67-68), "Si bien no han llegado hasta nosotros muchas obras mantenidas en su pureza e integridad, a la manera de Ollántay y de Atawallpa, en cambio hay testimonios suficientes que prueban que el teatro era un arte muy conocido entre los indios de la era precolombina." (Lara, 1979[1947]): 93), "El lenguaje, la técnica y la esencia del poema pertenecen íntegramente al pueblo quechua. La obra nació antes de que los invasores hubiesen atrapado en el cepo de su intervención al espíritu del indio." (Lara, 1979[1947]): 107). Poco importaba que no conociera todavía ningún tex to quechua de la obra. La traducción parcial de Unzueta permitía reconstruir el original con toda fidelidad. Este ya existía en la mente del escritor boliviano. Desde entonces, ¿cómo hubiera podido resistirse a darle una existencia también para los demás? El descubrimiento de Debate, en 1952, y la publicación de Conquista, en 1955, le dieron los elementos que todavía le faltaban para plasmar la obra en su integralidad. El autor de la Tragedia no puede haber sido sino el propio Jesús Lara.

\section{EL TÍTULO DE LA OBRA Y LA FECHA DEL MANUSCRITO}


El título de la obra “descubierta” por Lara en 1955, Atau Wallpajp’uchukakuyninpa wankan, es decir "wanka del fin de Atahuallpa", corresponde exactamente a la expectativa creada por él, en 1947, en torno al género del wanka. En La poesía quechua, ya lo había definido como un género dedicado a "lamentar la desaparición de los seres queridos o de los personajes ilustres, exaltando al mismo tiempo sus virtudes y sus hazañas" (1979[1947]): 93) y había colocado arbitrariamente en esa categoría el poema “Apu inka Atawallpaman”, publicado por J.M.B. Farfán en 1942 (pp. 543-546). Este poema, que no parece anterior al siglo XIX, según Lara "debió haberse compuesto al difundirse la noticia de la muerte de Atahuallpa" (Lara, 1979[1947]): 92). No tenía motivo alguno para caracterizar ese poema como wanka. En la cultura actual del sur del Perú, este término designa un canto plañidero vinculado a los ritos del ciclo agrícola (29). Sin embargo, existía un precedente, en los estudios quechuistas, que hacía del wanka el equivalente quechua del género de la Tragedia. Se trata de la Gramática del quechuista ayacuchano José Dionisio Anchorena (1874) quien escribe: "El huancay y el aranhuay son poesías dramáticas, que no se cantan, correspondientes: el primero á la tragedia y el segundo á la comedia y se componen de versos sueltos ó asonantes de ocho á diez sílabas. Entre los dramas mas notables del quechua, se cuenta el de Ollanta, Usca Paucar, la muerte de Atahuallpa, la de Titu Cusi Yupanqui y otros pequeños que aun se representan en algunos pueblos del interior, en la octava del Corpus Cristi é invención de la cruz" (Anchorena, 1874: 140-141).

Lara conocía el libro de Anchorena ya que, sin mencionarlo, tomó de él la nomenclatura supuesta de varios de los géneros de la literatura incaica (30). Como se ve en la cita anterior, Anchorena ya había mencionado la existencia de una tragedia inca sobre el tema de "la muerte de Atahuallpa" y le atribuía pautas métricas que volvemos a encontrar en la Tragedia. Lara encontró en la Gramática de Anchorena una fuente de relativa antigüedad que corroboraba la autenticidad de la Tragedia. Para que la Gramática pudiera funcionar como testigo de la existencia de la Tragedia, debió parecerle preferible que el manuscrito de ésta fuera anterior a la fecha de edición de aquella. Pero no lo podía ser demasiado ya que la elaboración de dos páginas de un manuscrito supuestamente colonial le hubiera planteado a Lara grandes dificultades de paleografía. La fecha de 1871, que aparece en el manuscrito de la Tragedia, era una de las fechas más verosímiles, vistas las circunstancias, que pudiera elegir Lara para su manuscrito falsificado.

\section{LAS FOTOCOPIAS DE LA PRIMERA Y LA ÚLTIMA PÁGINA DEL MANUSCRITO}

(29) No parece existir en el quechua de Cochabamba, lo que explicaría la facilidad con la que Lara le pudo hacer sufrir esa adaptación semántica.

(30) Ninguna fuente colonial proporciona términos quechuas para "tragedia" y "comedia" e ignoramos lo que llevó a Anchorena a dar los nombres de wanka y aranway a estos géneros. Es probable que no tuviera mayor base para ello. Lo sugiere su Traducción de la ley orgánica de municipalidades en lo relativo a los concejos de distrito (Lima, Imprenta del Estado, 1873), llena de arcaismos arbitrariamente adaptados y de neologismos de oscura composición. El invento terminológico de Anchorena nunca tuvo éxito hasta que Lara lo retomara. 
Por obvias razones de prudencia, Lara no podía haber escrito las dos páginas del manuscrito de su puño y letra. Debió hacer una primera versión que mandó copiar por una persona al parecer muy poco acostumbrada a escribir: su letra es vacilante y trazada con lentitud. Obviamente, quien tenía esas dificultades para escribir difícilmente pudo concebir el proyecto de copiar una obra de tan largo aliento como la Tragedia ni recibir el encargo de hacerlo. Por lo tanto, cuesta creer que, en algún momento, el manuscrito tuviera más existencia que la de su primera y de su última página. Ahora bien, en esa primera página, y en la versión normalizada que de ella publicó Lara, el verbo yanancha-, que en principio significa "aparear", aparece dos veces con el sentido inexplicable de "ver (en sueños), adivinar". No vuelve a cobrar ese sentido luego en toda la obra donde encontramos más bien, repetidas veces, el verbo unancha- con ese sentido. La doble ocurrencia de yanancha-, en la primera página del manuscrito sólo puede explicarse como un error del copista a quien Lara encargó la elaboración de la primera página del manuscrito. En efecto, unancha-, en el sentido de "ver (en sueños), adivinar", no parece común en el quechua boliviano moderno (31). Por este motivo, es probable que el copista interpretara el término unancha-como yanancha-, más familiar para él. Luego no le quedó más remedio a Lara que reproducir ese error en su versión normalizada. Trató de despistar al lector utilizando otra vez el verbo yanancha-, un poco más adelante, en un contexto en el cual tiene su auténtico sentido de "aparear" al mismo tiempo que, nominalizado con el perfectivo -sqa, adjetiva el término muspay "soñar":

Yananchasqa muspayniypi

auqa q'illay runakuna

ch'ichimunku míllay míllay...

(p. 58)
Durante los dos sueños

hombres cubiertos de irritante hierro

innumerables han brotado...

\section{CONCLUSIÓN}

Convencido del origen incaico de las representaciones de la muerte de Atahuallpa, Lara intentó reconstruir un original, o algo cercano a ello, a partir de los textos que conocía y de sus conocimientos de la lengua antigua. Como lo hemos visto, éstos eran en realidad muy limitados y Lara creyó que el quechua de la Tragedia, es decir un quechua boliviano moderno salpicado de unos pocos arcaismos era, como lo afirmó él mismo, "el antiguo cuzqueño [...] casi puro" (p. 24). Desde un punto de vista lingüístico, el resultado es bastante fallado pero su éxito ha quedado asegurado por la falta de conocimiento del quechua que han tenido los estudiosos que han tratado de la cuestión.

La Tragedia reúne todas las características de la tradición de la falsificación en la literatura occidental: la de un documento original, vagamente mencionado en una fuente antigua, encontrado en un lugar difícilmente accesible e impreciso (32), luego copiado y finalmente perdido. Es delicado especular sobre las motivaciones de Lara para realizar esta falsificación, y, más aún, sobre los problemas intelectuales y morales que

(31) Por lo menos, Herrera \& Sánchez de Lozada (1983) no lo registran en ese sentido.

(32) Lara apunta solamente que el dueño vivía "en una comarca de la provincia Alonso de Ibáñez, en Potosí” (p. 23). 
ésta le pudo plantear. Ante las extrañezas que advirtió en el texto de la Tragedia, J.-P. Husson no dejó de considerar la posibilidad de una superchería de parte de Lara aunque la rechazó enseguida con un argumento poco científico: "en efecto, ¿cómo pensar, sin acusarle de un maquiavelismo diabólico, que hubiera transformado, e incluso enteramente compuesto, el documento que publicó?" (33). Por mi parte, no creo que su falsificación literaria refleje intenciones tan negras. Al contrario, su quehacer intelectual no se situaba dentro de un contexto académico filológico, que no existía en Bolivia. Pretendía más bien reivindicar al "indígena" y su cultura, en una sociedad que no solía considerar al quechua y a quienes hablaban este idioma como portadores de cultura. A través de sus novelas y sus ensayos, Lara llevaba a cabo un combate ideológico, casi solitario en Bolivia, dentro del cual la crítica de las fuentes, la dialectología, la lingüística histórica y el cuestionamiento de los conocimientos establecidos no tenían pertinencia alguna. Defendió así denodadamente la "incanidad" de cuanto texto quechua de autor desconocido cayera en sus manos y buscó dar a los textos antiguos una legibilidad que de por sí no tenían para un quechuahablante moderno, agregando, quitando o cambiando sílabas y palabras hasta conseguir textos interpretables a partir de la variedad que conocía, es decir el quechua boliviano (34). Su reescritura de los textos antiguos produjo resultados que generalmente no tienen mucho en común, ni en la letra ni en el sentido, con lo que un trabajo filológico permite establecer. Pero, por lo menos, de esa forma, los textos adquirieron cierta existencia - aunque falaz- para un amplio público. En realidad, no existe mucha distancia entre esa reescritura de los textos y la elaboración de la Tragedia. En efecto, desde su propio punto de vista, Lara no transformó esta última ni la compuso enteramente sino que le devolvió su pureza y su integridad originales partiendo de los fragmentos de lo que él creía ser una tradición de origen incaico. Tal vez, en cierta forma, Lara estaba persuadido de haber encontrado, mediante esa reconstrucción, la Tragedia original. Pero para que su descubrimiento intelectual tuviera el impacto merecido, tenía que hacerlo pasar por un descubrimiento material y fraguar la ficción del manuscrito. Es probable que esta pequeña mentira no le pareciera demasiado importante en relación con lo que estaba en juego: demostrar que los incas habían tenido una gran literatura, con las consecuencias que esto tendría para el estatus del quechua y de la cultura de sus hablantes dentro de las sociedades andinas. Lejos de recoger una "visión de los vencidos" (35), la Tragedia debe estudiarse como una manifestación de la literatura quechua indigenista. El interés que presenta no resulta por ello disminuido.

(33) “comment penser, en effet, sauf à l'accuser d'un machiavélisme diabolique, qu'il aurait transformé, voire composé de toutes pièces le document qu'il a publié?” (1997: 92).

(34) He mencionado un ejemplo de ello en Joan de Santa Cruz Pachacuti Yamqui Salcamaygua, 1993: 136.

(35) Ni siquiera las versiones tradicionales pueden ser leídas como tales: en un artículo reciente, basado en un análisis de esas versiones, Pierre Duviols (2000) ha mostrado el origen colonial, erudito y eclesiástico de las mismas. 


\section{Referencias citadas}

ANCHORENA, J. D., 1874 - Gramática quechua ó del idioma del Imperio de los Incas; Lima.

ANÓNIMO, 1971 - Ullanta. Drama quechua del tiempo de los Incas; Librería editorial "Juventud"

BALMORI, C. H., 1955 - La conquista de los españoles y el teatro indígena americano; Tucumán: Universidad Nacional de Tucumán.

BELTRÁN, C. F., 1891 - Civilización del indio. Antología quichua dividida en dos partes, profana y sagrada; Oruro: tipografía de El Progreso.

BEYERSDORFF, M., s.f., - Historia y Drama Ritual en Los Andes Bolivianos (siglos XVI-XX); La Paz: Plural Editores - Facultad de Humanidades y Ciencias de la Educación - UMSA.

“DEBATE DE INCAS”, 1987 - Kuntur. Perú en la cultura, $\mathbf{n}^{\circ} 5$ (mayo-junio); Lima.

DUVIOLS, P., 2000 - Las representaciones andinas de "La muerte de Atahuallpa". Sus orígenes culturales y sus fuentes. In: Tradición culta y sociedad colonial. La formación del pensamiento iberoamericano (Karl Kohut \& Sonia Rose, eds.); Madrid: colección iberoamericana.

ESTENSSORO, J. C., 1997 - Du paganisme à la sainteté. L'incorporation des Indiens du Pérou au catholicisme. 1532-1750. Thèse de doctorat Nouveau Régime en Histoire et Civilisations. École des Hautes Études en Sciences Sociales.

FARFÁN, J.M.B., 1942 - Poesía folklórica quechua, 117 poemas quechuas en el idioma original y traducidos al castellano. Revista del Instituto de Antropología de la Universidad nacional de Tucumán, volumen 2, número 12; Tucumán.

HERRERO, J. \& SÁNCHEZ DE LOSADA, F., 1983 - Diccionario quechua. Estructura semántica del quechua cochabambino contemporáneo, 581p.; Sucre: C.E.F.CO.

HUSSON, J.-P., 1997 - Une survivance du théâtre des Incas : le cycle dramatique de la mort d'Atawallpa. Thèse pour le doctorat d'État ès-lettres. Directeur de recherches Mme Bénassy. Université de la Sorbonne Nouvelle - Paris III, 1137p., 3 tomes.

ITIER, C., 2000 - El teatro quechua en el Cuzco. Tomo II. Indigenismo, lengua y literatura en el Perú moderno, 332p.; Cuzco: Institut Français d'Études Andines - Centro de Estudios Regionales Andinos "Bartolomé de Las Casas".

LARA, J., 1961 - La literatura de los Quechuas. Ensayo y antología; La Paz: Librería editorial "Juventud".

LARA, J., 1979[1947] - La poesía quechua; México: Fondo de Cultura Económica.

LARA, J., 1989 - Tragedia del fin de Atawallpa; La Paz: Ediciones del Sol - Los Amigos del Libro. Versión en español y estudio preliminar de Jesús Lara. Edición bilingue.

LASTRA, Y., 1968 - Cochabamba Quechua Syntax; Paris: Mouton.

MENESES, T., 1983 - Teatro quechua colonial. Antología; Lima: ediciones Edubanco.

PINAYA, R. F., 1991 - Qhichwa willakuykuna. Cuentos qhichwa; Aruwiyiri: Taller de Historia Oral Andina.

SANTA CRUZ PACHACUTI YAMQUI SALCAMAYGUA, J. de, 1993 - Relación de antiguedades deste reyno del Piru, 276p.; Cuzco, Institut Français d'Études Andines Centro de Estudios Regionales Andinos "Bartolomé de Las Casas". Estudio etnohistórico y lingüístico de Pierre Duviols y César Itier.

SILVA-SANTISTEBAN, R. (comp.), 2000 - Antología General del Teatro Peruano. I. Teatro Quechua, 581p.; Lima: Banco Continental - Pontificia Universidad Católica del Perú. Selección, prólogo y bibliografía de Ricardo Silva-Santisteban.

UNZUETA, M., 1945 - Valle. Cochabamba: Editorial "La Época".

WACHTEL, N., 1971 - La vision des vaincus. Les Indiens du Pérou devant la Conquête espagnole., 395p.; Paris: Éditions Gallimard. 